\title{
O agir leigo e o cuidado em saúde: a produção de mapas de cuidado
}

\author{
Lay agency and healthcare: producing healthcare \\ maps
}

\author{
Agencia laica y producción de salud: elaboración \\ de mapas de salud
}

\footnotetext{
1 Escola Paulista de

Medicina, Universidade

Federal de São Paulo, São

Paulo, Brasil.

2 Instituto Superior de

Ciências do Trabalho e

da Empresa, Instituto

Universitário de Lisboa,

Lisboa, Portugal.

${ }^{3}$ Faculdade de Ciências

Médicas, Universidade

Estadual de Campinas,

Campinas, Brasil.

Correspondência

L. C. O. Cecilio

Departamento de Medicina

Preventiva, Escola Paulista

de Medicina, Universidade

Federal de São Paulo.

Rua Botucatu 740

São Paulo, SP 04023-062,

Brasil.

luizcecilio60@gmail.com
}

\begin{abstract}
This study aimed to characterize which regulatory logics (other than government regulation) result in healthcare output, using a two-stage qualitative study in two municipalities in the ABCD Paulista region in São Paulo State, Brazil. The first stage included interviews with strategic actors (managers and policymakers) and key health professionals. The second phase collected life histories from 18 individuals with high health-services utilization rates. An analysis of the researchers' involvement in the field allowed a better understanding of the narratives. Four regulatory systems were characterized (governmental, professional, clientelistic, and lay), indicating that regulation is a field in constant dispute, a social production. Users' action produces healthcare maps that reveal the existence of other possible health system arrangements, calling on us to test shared management of healthcare between health teams and users as a promising path to the urgent need to reinvent health.
\end{abstract}

Health Care Coordination and Monitoring; Delivery of Health Care; Qualitative Research
Luiz Carlos de Oliveira Cecilio ${ }^{1}$

Graça Carapinheiro ${ }^{2}$

Rosemarie Andreazza 1

Ana Lúcia Medeiros de Souza ${ }^{1}$

Maria da Graça Garcia Andrade 3

Silvia Maria Santiago 3

Consuelo Sampaio Meneses 1

Denizi Oliveira Reis 1

Eliane Cardoso Araújo 1

Nicanor Rodrigues da Silva Pinto 1

Sandra Maria Spedo 1

\section{Resumo}

O estudo teve como objetivo caracterizar que outras lógicas de regulação, para além da governamental, resultam na produção do cuidado, por meio de pesquisa qualitativa realizada em dois municípios do ABCD Paulista, São Paulo, Brasil, em duas etapas. Na primeira, foram realizadas entrevistas com atores estratégicos (gestores e politicos) e atores-trabalhadores-chave. Na segunda, foram coletadas histórias de vida de 18 pessoas com elevada frequência de utilização de serviços de saúde. A análise de implicação dos pesquisadores com o campo permitiu uma melhor compreensão das narrativas. Foram caracterizados quatro regimes de regulação (governamental, profissional, clientelístico e leigo), indicando que a regulação é campo em permanente disputa, é uma produção social. Com o seu agir, os usuários produzem mapas de cuidado que nos indicam como há outros arranjos possíveis de sistemas de saúde, representando um convite para experimentarmos a cogestão do cuidado entre equipes e usuários, como caminho promissor para a inadiável necessidade de reinvenção da saúde.

Regulação e Fiscalização em Saúde; Assistência à Saúde; Pesquisa Qualitativa 


\section{Introdução}

Há razoável literatura sobre definições de regulação 1,2,3. Na sua dimensão governamental, a regulação assistencial é entendida como a "disponibilização da alternativa assistencial mais adequada à necessidade do cidadão, de forma equânime, ordenada, oportuna e qualificada, efetivada por meio de complexos reguladores, articulada com a avaliação das necessidades de saúde, planejamento, regionalização, programação $e$ alocação de recursos, além das ações de avaliação e controle" 4

Fala-se, portanto, de disponibilização da assistência de forma oportuna e qualificada, o que nos leva a apontar uma tríplice definição de acesso: ele é um "chegar lá”, no tempo adequado, obtendo o que se precisa. O estudo partiu do pressuposto de que essa definição (qual o lugar, o tempo e o cuidado adequado?) depende dos atores que a enunciam, sendo, portanto, marcada por dissensos, o que nos permite afirmar que é da natureza da regulação ser campo de conflitos e disputas, muito mais do que um simples ordenamento burocrático-administrativo. Assumindo que regulação são regras do jogo que vão sendo socialmente produzidas e negociadas, é possível pensar a regulação como uma produção social 5,6,7,8.

Ao olhar a regulação sobre tal prisma, mais do que buscar os marcos jurídicos e regulatórios dos sistemas de saúde, e/ou sua historicidade, e como os atores sociais governamentais constroem os "complexos reguladores", interessava compreender como outros atores, em particular os usuários, atuam na regulação do sistema na busca pelo cuidado em saúde. Estudos anteriores enfocam as legislações e os modelos sobre a "regulação na saúde" 1,2,3,9,10,11, entretanto, não localizamos artigos sobre como os usuários atuam ativamente nos processos regulatórios. $\mathrm{O}$ objetivo central da investigação, e que lhe confere originalidade, foi caracterizar as várias lógicas de regulação do acesso e consumo dos serviços de saúde existentes, para além da regulação governamental, com particular ênfase no que está sendo denominado, no artigo, de "agir leigo".

\section{Percurso metodológico}

O estudo, de caráter qualitativo, foi realizado em dois municípios de grande porte da região do ABCD Paulista, São Paulo, Brasil. As cidades, apesar de suas histórias distintas de construção do Sistema Único de Saúde (SUS), contam hoje com uma rede organizada de atenção básica, especializada e hospitalar, incluindo serviços de urgência e emergência, além de outras unidades de saúde de maior densidade tecnológica de referência regional. A despeito das diferenças socioeconômicas e demográficas das cidades, seus perfis epidemiológicos são semelhantes.

Na primeira fase da pesquisa, de caráter exploratório, foram realizadas entrevistas temáticas, em profundidade, com atores estratégicos dos municípios (prefeito, secretário de saúde e conselheiros municipais de saúde) e com profissionais selecionados do SUS municipal (enfermeiro, agente comunitário de saúde e médico) com longa história de inserção no sistema local. Elas tinham como objetivo buscar fazer uma "genealogia" dos sistemas locais de saúde, nos contextos sociopolíticos específicos de cada município.

Para a segunda fase do estudo, adotou-se o método biográfico 12,13, com a coleta das histórias de vida de usuários dos serviços de saúde. A abordagem biográfica 13,14, como preferem denominar alguns autores, tem sido empregada cada vez mais frequentemente pelas ciências sociais e humanas.

O desafio ao utilizar essa abordagem é o de produzir um conhecimento científico centrado na experiência humana e na memória que ela vai sedimentando. A tarefa é então a de construir, progressivamente, um corpo de hipóteses que sustentem a produção de um modelo, rico em descrições, de explicações e de interpretação de fenômenos da experiência humana, que permita algum grau de generalização e mesmo de reprodutibilidade 12,13,14.

Na saúde, o uso do método biográfico tem sido menos extensivo, podem-se destacar aqui os trabalhos realizados, entre outros, por Schraiber 15,16, Carapinheiro 17, Gomes 18, Andreazza et al. 19 e Other \& Ayres 20.

Porém, o uso da abordagem biográfica não tem sido linear no tempo nem mesmo consensual. Tal fato pode ser atribuído à forte "dose" de subjetividade que ela comporta por sua centralidade na experiência de vida singular narrada por um indivíduo. Segundo Houle 14 (p. 317), "após ter-se recusado o sujeito, por sobrecarregar demais na análise dos processos sociais, eis que se aplaude agora o seu retorno; o retorno de um sujeito que, na realidade, nunca havia partido". Para Arfuch 13 (p. 253), a volta ao biográfico "dar voz aos protagonistas" - pode ser visto como uma "das manifestações do esgotamento do estruturalismo e de sua elisão do sujeito e sua historicidade".

Corroborando essa ideia, Bertaux 12, um dos principais responsáveis pelo ressurgimento do método biográfico, afirma que, para a Sociologia, o que interessa é questionar a própria vida, ou si- 
tuações de vida, como um fenômeno social. Para Houle 14 (p. 323), isso é possível, "pois, por mais individuais que sejam os relatos, as histórias de vida (...) estes discursos dão acesso a uma prática que é também social". Então, para ele, é possível afirmar que "as histórias de vida são o resultado da elaboração de uma experiência ou de experiências (...) de vida, e que por mais singulares que elas sejam, podem ser consideradas como experiências da vida em sociedade" 14 (p. 326).

Foram entrevistados 18 usuários com o objetivo de reconstituir, a partir das suas experiências em processos de adoecimento, como acessam e utilizam os serviços de saúde. Eles foram indicados por agentes comunitários de saúde dos municípios estudados, tendo como critério serem pessoas que utilizam com elevada frequência os serviços de saúde. Na Tabela 1, estão descritas as principais características das pessoas entrevistadas.

Todas as entrevistas, da primeira e da segunda fase da pesquisa, foram gravadas em meio digital, com a anuência do entrevistado, que assinava o termo de consentimento livre e esclarecido, conforme aprovação do Comitê de Ética em Pesquisa da Universidade Federal de São Paulo (Unifesp; CEP 1669/10), e, posteriormente, transcritas.

Para análise do material empírico coletado a partir das histórias de vida dos usuários, os pesquisadores elaboraram narrativas de vida. Nelas, além de um retrato social do usuário, narrava-se a sua experiência da doença, reconstituindo-se a utilização dos serviços de saúde, os contatos profissionais, ou seja, as referências principais utilizadas; as experiências de ausência e presença dos serviços e do cuidado; e a percepção dos usuários sobre as barreiras, as facilitações e os "curtos-circuitos" na busca pelo acesso e consumo dos serviços de saúde. A partir daí, foram extraídos os elementos analíticos presentes em cada história biográfica: as intensidades, as visibilidades, as composições e os arranjos da regulação do acesso, os aprendizados dos usuários a partir de suas experiências, os significados atribuídos aos serviços, entre outros elementos. Todas as narrativas de vida foram objeto de discussão no grupo de pesquisadores em vários seminários de pesquisa.

A discussão dos resultados ora apresentada foi feita a partir da análise conjunta do material empírico coletado nas duas etapas da pesquisa.

\section{Resultados e discussão}

\section{Os regimes de regulação}

A regulação, como apontamos antes, é uma produção social, comportando, por isso mesmo, diferentes lógicas, racionalidades e processualidades ou regimes de regulação, conceito que será aprofundado adiante. A regulação, por essa perspectiva, seria a resultante sempre tensa e provisória do cruzamento de múltiplos regimes de regulação. A regulação governamental, aquela que vai sendo produzida pelo arsenal jurídicoinstituinte do SUS, baseia-se conceitual, ética e politicamente nos princípios de direitos e cidadania, com especial ênfase para as dimensões de universalidade (acesso universal para todos os cidadãos) e equidade (com adequação de cuidados particulares a necessidades específicas) O governo reivindica ser o regulador principal, senão o único capaz de garantir tais direitos. O problema é que nem todos os atores sociais atuam de acordo com isso, buscando mudar as regras do jogo, portanto, instituindo novos modos de regulação. A regulação é uma produção social que comporta múltiplos regimes de regulação. A regulação é processo permanentemente instituinte e, por isso mesmo, permanente palco de mudanças.

Os dispositivos legais formais (legítimos, no sentido weberiano de autoridade racional-legal do termo) de regulação são de competência governamental (regulação governamental) e se pretendem ordenadores do acesso. A regulação governamental é, ela mesma, resultado de disputas e acomodações de possibilidades assistenciais, e, embora se pretenda racional, ela própria é atravessada por múltiplos interesses e contradições. Trata-se, agora, de trabalhar com um pouco mais de cuidado e profundidade a categoria regime de regulação. Ela é uma categoria analítica de inspiração sociológica, em particular por sua ênfase no reconhecimento de regularidades sociais sincrônicas passíveis de serem reconhecidas e estudadas. Foi possível percebê-las na constituição e no funcionamento dos sistemas de saúde nos dois municípios estudados, em particular na primeira fase do estudo.

Foram identificados, já na primeira fase do estudo, quatro regimes de regulação: o regime de regulação governamental, o regime de regulação profissional, o regime de regulação clientelístico e o regime de regulação leiga 21 (Tabelas 2 , 3, 4 e 5). Poderíamos levantar a hipótese de que se o presente estudo fosse reproduzido em outros municípios, em futuros estudos, encontraria resultados semelhantes devido ao fato de os gestores municipais do SUS atuarem em campo 
Principais características das pessoas estudadas.

\begin{tabular}{|c|c|c|c|c|c|}
\hline Entrevistado & Sexo & $\begin{array}{l}\text { Idade } \\
\text { (anos) }\end{array}$ & Situação familiar & Situação de trabalho & Principais problemas de saúde \\
\hline Érica & Feminino & 44 & $\begin{array}{l}\text { Casada, } 3 \text { filhos, } \\
\text { moram todos juntos. }\end{array}$ & Aposentada. Foi ACS. & $\begin{array}{l}\text { Depressão pós-parto e } \\
\text { síndrome do pânico. }\end{array}$ \\
\hline Tulipa & Feminino & 47 & $\begin{array}{l}\text { Casada, } 1 \text { filho e uma neta. } \\
\text { O filho é enfermeiro. }\end{array}$ & $\begin{array}{c}\text { Do lar. Foi proprietária de um } \\
\text { restaurante. }\end{array}$ & $\begin{array}{c}\text { Diabetes mellitus, cardiopatia } \\
\text { e hemorragia ginecológica - } \\
\text { anemia. }\end{array}$ \\
\hline Lírio & Masculino & 64 & Casado, 3 filhas, uma já falecida. & $\begin{array}{l}\text { Aposentado. Foi operário da } \\
\text { indústria automobilística. }\end{array}$ & $\begin{array}{l}\text { HAS, diabetes mellitus e } \\
\text { cardiopatia. }\end{array}$ \\
\hline Miosótis & Feminino & 35 & $\begin{array}{l}\text { Casada, } 3 \text { filhos. } \\
\text { Moram todos juntos. }\end{array}$ & $\begin{array}{l}\text { Do lar. } \\
\text { Trabalhou com transporte. }\end{array}$ & Hipoglicemia e dor de cabeça. \\
\hline Hortênsia & Feminino & 72 & $\begin{array}{l}\text { Separada, } 3 \text { filhos, mora com o } \\
\text { marido, } 2 \text { filhas, o genro e uma } \\
\text { neta. Uma das filhas é ACS de } \\
\text { uma UBS. }\end{array}$ & $\begin{array}{c}\text { Aposentada. Trabalhou com } \\
\text { serviços domésticos. }\end{array}$ & $\begin{array}{c}\text { Artrose, asma, hérnia, HAS, } \\
\text { diabetes mellitus e dificuldades } \\
\text { auditivas. }\end{array}$ \\
\hline Orquídea & Feminino & 39 & $\begin{array}{l}\text { Casada, } 7 \text { filhos. } \\
\text { Moram todos juntos. }\end{array}$ & Do lar. Vendia bala no sinal. & $\begin{array}{c}\text { Filho especial: sequelas } \\
\text { neurológicas e motoras por } \\
\text { meningite. }\end{array}$ \\
\hline Manacá & Masculino & 57 & $\begin{array}{c}\text { Casado, } 4 \text { filhos, } 2 \text { netos. Moram } \\
\text { com eles uma filha e o genro. }\end{array}$ & $\begin{array}{l}\text { Aposentado. Foi operário da } \\
\text { indústria automobilística. }\end{array}$ & $\begin{array}{c}\text { Acidente de trabalho, hérnia de } \\
\text { disco, alcoolismo, HAS. }\end{array}$ \\
\hline Jasmim & Masculino & - & $\begin{array}{c}\text { Casado, } 1 \text { filha. } \\
\text { Mora com a esposa. }\end{array}$ & $\begin{array}{l}\text { Aposentado. Foi operário da } \\
\text { indústria automobilística. }\end{array}$ & $\begin{array}{c}\text { Acidente de trabalho - lesão na } \\
\text { coluna e grave lesão na mão. }\end{array}$ \\
\hline Rosa & Feminino & 48 & $\begin{array}{l}\text { Mora com o segundo marido e } \\
\text { o filho do primeiro casamento. }\end{array}$ & $\begin{array}{l}\text { Autônoma, vende produtos de } \\
\text { limpeza. Foi operária de uma } \\
\text { indústria alimentícia. }\end{array}$ & Câncer de mama. \\
\hline Margarida & Feminino & 52 & $\begin{array}{l}\text { Casada, } 4 \text { filhos, } 8 \text { netos. Mora } \\
\text { com o marido e o filho caçula. }\end{array}$ & $\begin{array}{c}\text { Diarista. Está sem trabalhar há } \\
\text { três anos. }\end{array}$ & $\begin{array}{l}\text { Artrite reumatoide, HAS e } \\
\text { diabetes mellitus. }\end{array}$ \\
\hline Magnólia & Feminino & 57 & $\begin{array}{l}\text { Casada, } 2 \text { filhos que vivem com } \\
\text { ela, além também de uma neta } \\
\text { e a mãe. }\end{array}$ & Do lar. & $\begin{array}{l}\text { Obesidade mórbida com } \\
\text { dificuldade de locomoção. }\end{array}$ \\
\hline Flor de Bambu & Masculino & 73 & $\begin{array}{l}\text { Casado, } 6 \text { filhos. } \\
\text { Mora com a esposa. }\end{array}$ & Aposentado. Foi metalúrgico. & $\begin{array}{c}\text { HAS, doença pulmonar } \\
\text { obstrutiva crônica e cardíaco. }\end{array}$ \\
\hline Cravo & Masculino & 54 & $\begin{array}{c}\text { Casado, } 2 \text { filhos, vive com a } \\
\text { esposa e um filho. }\end{array}$ & Aposentado. Foi metalúrgico. & $\begin{array}{l}\text { HAS, insuficiência cardíaca } \\
\text { congestiva e catarata. }\end{array}$ \\
\hline Amarílis & Feminino & 70 & $\begin{array}{c}\text { Viúva, uma filha e } 3 \text { netos. Mora } \\
\text { sozinha, em casa contígua } \\
\text { à da irmã. }\end{array}$ & $\begin{array}{c}\text { Aposentada, foi faxineira e } \\
\text { artesã (comercializava em casa). }\end{array}$ & $\begin{array}{l}\text { HAS, diabetes mellitus e } \\
\text { cardiopata. }\end{array}$ \\
\hline Violeta & Feminino & 70 & $\begin{array}{l}\text { Solteira, } 2 \text { filhos. Mora com o } \\
\text { filho, a filha, o genro e } \\
\text { dois netos. }\end{array}$ & $\begin{array}{l}\text { Aposentada, serviços gerais de } \\
\text { limpeza, em serviços do } \\
\text { SUS local. }\end{array}$ & Atualmente, câncer de mama. \\
\hline Camélia & Feminino & 52 & $\begin{array}{l}\text { Viúva, um filho. Mora com a mãe } \\
\text { e com o filho. }\end{array}$ & $\begin{array}{c}\text { Aposentada, foi costureira e } \\
\text { babá. }\end{array}$ & $\begin{array}{l}\text { HAS, problemas renais e } \\
\text { transplante de rim. }\end{array}$ \\
\hline Jacinto & Masculino & 60 & $\begin{array}{c}\text { Casado, vive com a esposa e } \\
\text { uma neta que criam. }\end{array}$ & $\begin{array}{l}\text { Aposentado por invalidez, } \\
\text { foi vigia de uma metalúrgica. }\end{array}$ & $\begin{array}{c}\text { Paraplégico há } 17 \text { anos (foi } \\
\text { baleado no trabalho como } \\
\text { vigia). }\end{array}$ \\
\hline Dália & Feminino & 57 & $\begin{array}{l}\text { Vive com o marido, metalúrgico } \\
\text { aposentado. }\end{array}$ & $\begin{array}{l}\text { Do lar, mas faz costuras para } \\
\text { fora. }\end{array}$ & $\begin{array}{c}\text { Artrose, câncer de ovário, } \\
\text { nódulo benigno de tireoide e } \\
\text { HAS. }\end{array}$ \\
\hline
\end{tabular}

ACS: agente comunitário de saúde; HAS: hipertensão arterial sistêmica; SUS: Sistema Único de Saúde; UBS: unidade básica de saúde. 
Tabela 2

Características do regime de regulação governamental.

\section{Características}

\begin{tabular}{|c|c|}
\hline Atores & ores; equipes de regulação; formuladores da política. \\
\hline $\begin{array}{l}\text { Controle de } \\
\text { recursos }\end{array}$ & $\begin{array}{l}\text { A autoridade formal de legislar, de normalizar, de alocar recursos visando, por exemplo, à ampliação de oferta, seja via contratação } \\
\text { de pessoal, seja pela compra de serviços do setor privado. No limite, tem autoridade para a intervenção em serviços privados } \\
\text { (desapropriações, intervenções administrativas, outros) alegando-se a defesa de direitos públicos. }\end{array}$ \\
\hline $\begin{array}{l}\text { Modos de } \\
\text { operação }\end{array}$ & $\begin{array}{l}\text { 1. Regulação governamental burocrática (vertical, normativa, centralizada): atua segundo os princípios burocráticos de autoridade } \\
\text { legítima, competência técnica, comunicação formal, impessoalidade, segundo as definições weberianas de burocracia. } \\
\text { 2. Regulação governamental negociada (pactuada, descentralizada, com compartilhamento e responsabilidades): atua segundo os } \\
\text { princípios do agir comunicativo, adotando regras flexíveis e contratualizadas entre os vários atores. }\end{array}$ \\
\hline Produtos & $\begin{array}{l}\text { Os protocolos com critérios de encaminhamento; } \\
\text { A disponibilização de vagas em serviços de saúde de variadas complexidades; } \\
\text { A definição de responsabilidades dos vários serviços; } \\
\text { O estabelecimento de fluxos preferenciais entre os serviços; } \\
\text { As capacitações profissionais; } \\
\text { A construção de grandes redes de cuidado formalizadas, ordenadas e estáveis, na direção do que o Ministério da Saúde/ } \\
\text { Organização Pan-Americana da Saúde vem propondo, como as redes temáticas de cuidado } 19 .\end{array}$ \\
\hline Resultados & $\begin{array}{l}\text { Aumentar a disponibilidade ou oferta de serviços para produzir a integralidade do cuidado; } \\
\text { Garantir maior chance de acesso para as pessoas que mais precisam ser cuidadas (produzir equidade no sistema de saúde); } \\
\text { Garantir cobertura para uma ampla rede de atenção básica; } \\
\text { Utilização mais criteriosa e racional dos recursos. }\end{array}$ \\
\hline
\end{tabular}

Tabela 3

Características do regime de regulação profissional.

\section{Características}

\begin{tabular}{|c|c|}
\hline Atores & Médicos e outros profissionais de saúde. \\
\hline Controle de & Os contatos pessoais; \\
\hline recursos & O "controle do carimbo" no caso dos médicos; \\
\hline \multirow[t]{5}{*}{$\begin{array}{l}\text { Modos de } \\
\text { operação }\end{array}$} & $\begin{array}{l}\text { Burocrático: subordina-se à regulação formal, desobriga-se, atua como operador das regras governamentais. O profissional como } \\
\text { "agente" ou operador da regulação governamental. }\end{array}$ \\
\hline & $\begin{array}{l}\text { Criativo: aprende a usar e "flexibilizar" as regras da regulação formal a depender do que ele avalia serem as necessidades do } \\
\text { usuário. Produz regras informais. }\end{array}$ \\
\hline & Independente: aquele que "corre por fora" do sistema formal, usa contatos pessoais, faz prevalecer a inserção profissional sobre \\
\hline & a institucional, porque é na sua comunidade profissional alargada que encontra o principal sistema de referência para o seu agir \\
\hline & profissional. \\
\hline \multirow[t]{2}{*}{ Produtos } & A criação de circuitos quase sempre invisíveis para os gestores; \\
\hline & A atualização permanente de regras informais. \\
\hline \multirow{2}{*}{ Resultados } & Criação de fluxos de circulação mais ágeis e resolutivos para determinados pacientes; \\
\hline & Produção de iniquidades ou favorecimentos para determinados grupos de pacientes. \\
\hline
\end{tabular}




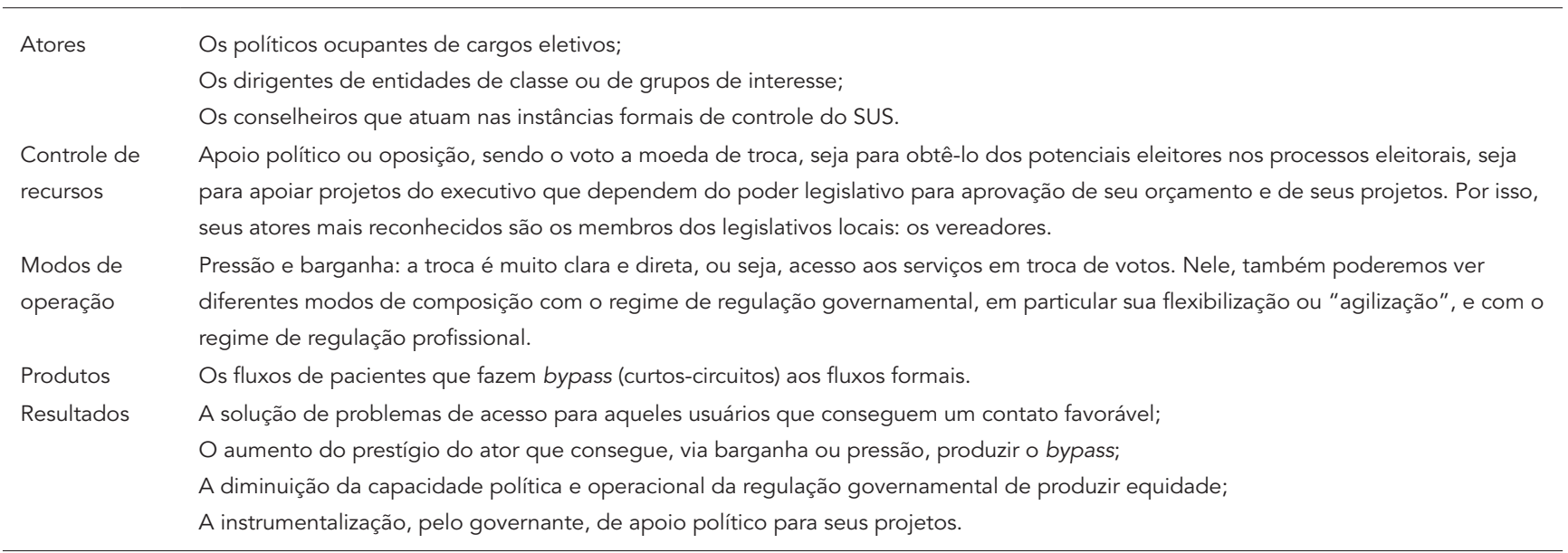

SUS: Sistema Único de Saúde.

altamente normalizado e regulamentado pelo Ministério da Saúde.

Dois esclarecimentos devem ser feitos sobre o conceito de regime de regulação. O primeiro é que os regimes de regulação definidos podem ser considerados como tipos ideais, no sentido empregado por Max Weber, tendo sido de muita valia para a sistematização preliminar e produção de inteligibilidade para o extenso material que ia sendo produzido, servindo como guia perante a complexidade do que se apresentava 22. Para compor os regimes de regulação, foram caracterizados seus atores (sempre há atores reconhecíveis, há ação humana, há objetivos e interesses), os recursos que mobilizam, seus modos de operação e, por fim, os produtos ou resultados da ação de seus atores (Tabelas 2, 3, 4 e 5).

O segundo esclarecimento é que a opção pelos regimes de regulação como tipos ideais esteve sempre marcada por uma tensão entre a observação de regularidades que permitiam enunciar "regimes" e a extrema diversidade de arranjos, soluções, composições que também podia se observar a partir das narrativas de vida dos usuários.

A variedade de arranjos e soluções produzidos por cada usuário, reconhecidos a partir de suas histórias de vida, frequentemente arrastava os pesquisadores na direção de adotar um conceito outro que não fosse o de regime de regulação leiga, por conta da forte ênfase desse nas regularidades. Tudo nos parecia tão singular, tão contingente, tão dependente de acasos e en- contros que não parecia adequado falar de um regime de regulação leiga, de modo que nos foi parecendo cada vez mais apropriado falar de um "agir leigo", mesmo que referenciado aos outros regimes de regulação.

Certeau 23 utiliza o conceito de "tática", formulado em investigações sobre as práticas cotidianas, quando identifica as ações que os indivíduos desenvolvem para lidar com os constrangimentos e limitações dos sistemas instituídos. E, por isso, o usuário circula no terreno dos limites e possibilidades que lhe são impostos, de modo que, diferente do propagado, as pessoas não são vítimas passivas dos sistemas, ao contrário, atuam ativamente neles, produzindo várias maneiras de usá-los.

No mesmo sentido, o protagonismo dos usuários perante as restrições do sistema de saúde foi apontado em pesquisa de Carapinheiro 17 , guardando ressonância com os conceitos de "o doente informador privilegiado" 24, "doente profissional” 25, conceitos que guardam semelhança entre si, em função da forte ênfase posta na potência de criação e invenção da ação humana.

Se bem pensado, há agir profissional, agir governamental, agir político e agir leigo que vão assumindo configurações singulares em cada contexto sócio-histórico-político específico. Assim, poderíamos dizer que há "agires" que vão resultando em regulações, que podem ser vistas como a expressão de regimes de regulação (governamental, profissional, clientelística e leigo), conceitos correlatos, constructos teóricos, que 


\section{Características}

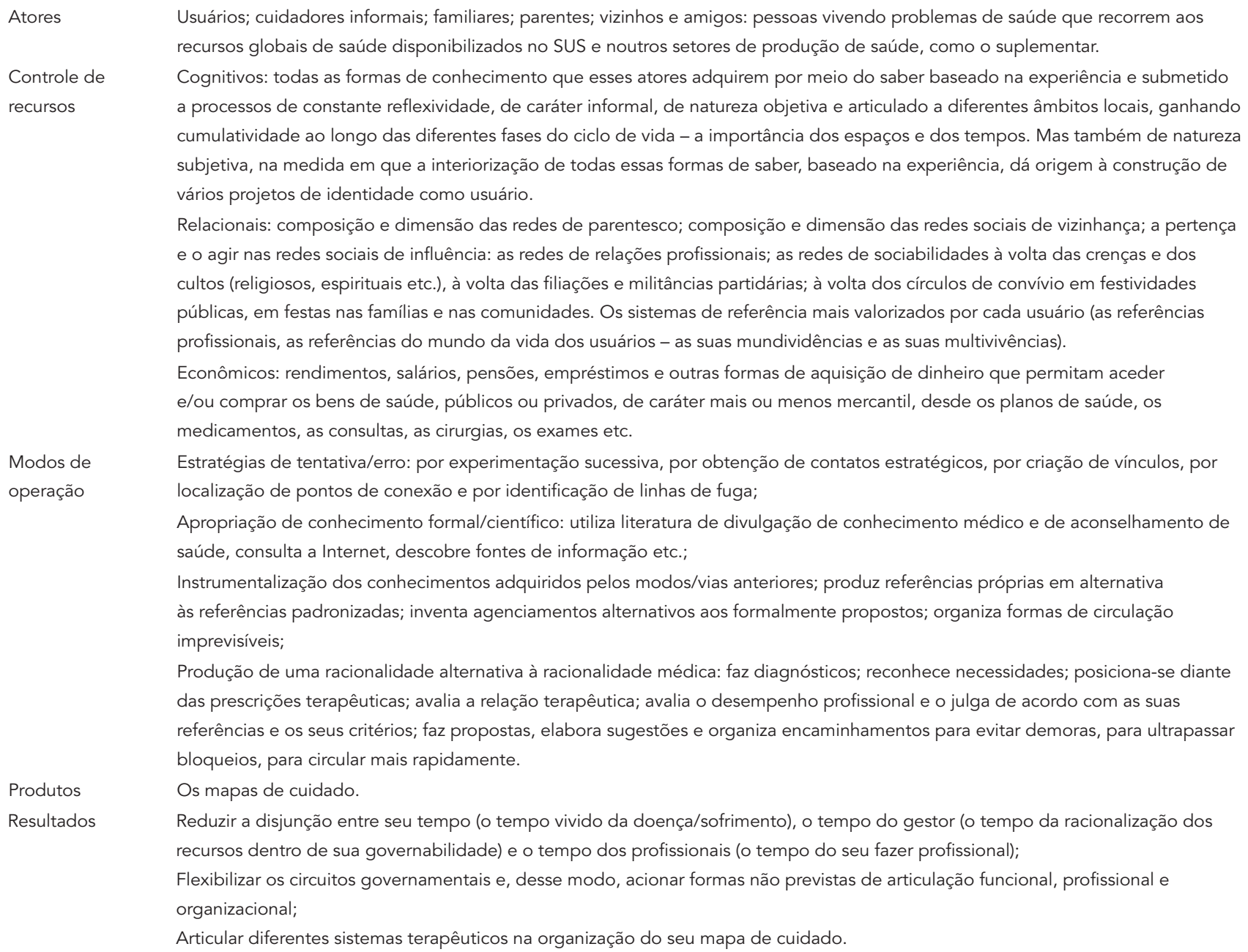

assumem nuances diferentes no correr do texto, embora referenciados à mesma ideia para fins da investigação.

\section{O agir leigo e a produção de mapas de cuidado}

As duas fases da pesquisa permitiram a observação da regulação a partir de duas perspectivas bastante diferenciadas, embora complementares quando olhadas em conjunto. Na primeira fase, quando foram ouvidos gestores, profissionais de saúde e conselheiros, foi possível caracterizar: (a) as dificuldades de gestores municipais para a implantação efetiva do SUS, em particular para garantir o acesso aos serviços de saúde na qualidade e rapidez demandadas pela população, limitados por uma baixa governabilidade caracterizada, entre outras coisas, pela dificuldade de fixação de médicos nas equipes de saúde, pela insuficiência dos recursos financeiros, pela baixa oferta de algumas especialidades na cidade $\mathrm{e}$ pela não gestão de equipamentos regionais (sob gestão do estado) para compor redes mais completas de cuidado; (b) a importância da regulação clientelística, em particular a realizada pelos vereadores; (c) a força da regulação profissional, em particular dos médicos, mas não só deles, pois vários outros profissionais de saúde também regulam. Já nessa fase exploratória da pes- 
quisa surgiram as primeiras indicações de que os usuários também teriam um peso importante na regulação, fato, em geral, desqualificado pelos atores organizacionais, quase sempre caracterizado como uma "disfunção". Esse fato passou a ser nosso foco principal de interesse.

A regulação clientelística surgiu com muita intensidade quando os secretários de saúde dos dois municípios falam, por exemplo, de como era a regulação e do que têm feito para mudá-la em suas cidades, como podemos ver neste relato: "Tinha o seguinte (...) Central de Vagas o que era? Receber pedidos de vereadores para fazer agendamento, então as guias de interconsulta aqui eram assim: 'Quem indicou?' Então o vereador pastor fulano de tal, vereador fulano de tal, deputado tal, (...) Era uma prática institucionalizada que ainda permanece em alguns gabinetes". Ou, como reconhece o outro secretário: “Agora aqui sempre teve uma prática política da secretaria da saúde, particularmente com os vereadores e com os conselheiros extremamente paternalistas".

A regulação profissional pode ser identificada na fala de um profissional: "Muitas vezes quando a gente precisa que um paciente seja encaminhado mais rápido, a gente consegue conversar com o pessoal da regulação e passar. Não é tão fácil assim, entendeu? Mas existe esse acesso e boa vontade das pessoas". Também é possível identificar uma ação mais autônoma dos profissionais, resumida desta forma por outra profissional: “Então, muitos casos, nós conseguimos, através de amigos (...) Ele [paciente] precisa de uma transferência em 'tal' e é o 'disque amigo' que funciona mais que as vias normais. (...) 60, 70\%, os casos mais graves o que funciona é o 'disque amigo', né? Porque a gente conta a situação do paciente, $e$ o amigo lá do outro lado: 'Vamos ver o que a gente pode fazer".

Na segunda fase da investigação, a partir das narrativas de vida dos usuários, foi ficando mais claro o protagonismo que as pessoas vivendo situações de doença exercem na produção de seus "sistemas de saúde" nos interstícios dos sistemas de saúde formais, estatal ou de mercado. A ideia de que as pessoas são produtoras de "seus sistemas de saúde" pode ser considerada a principal contribuição do estudo, representando um convite para um giro conceitual sobre como "temos pensado" a configuração do SUS.

Aliás, a expressão "temos pensado" passou a ser problematizada no momento da análise dos dados. Boa parte dos pesquisadores apresentava o que denominamos, no correr da pesquisa, de "duplo ou tríplice estatuto", isso é, éramos, ao mesmo tempo, pesquisadores, profissionais de saúde (muitos médicos com atuação na própria rede pública) e gestores ou ex-gestores. E, ainda, poucos de nós usam o sistema público de saúde de modo regular, na medida em que boa parte dos pesquisadores faz uso de planos privados de saúde para compor seu próprio cuidado e o de seus familiares. Qual seja o nosso modo de "produzir o objeto", de organizar a pesquisa, com seus pressupostos, perguntas, objetivos e metodologia, já vem "contaminado" por nossa inserção prévia no "mundo pesquisado". Tínhamos que reconhecer que havia um "nós" que atravessava todos os momentos da pesquisa, desde o desenho geral do estudo até o momento de análise do material que ia sendo produzido no campo. Um "nós naturalizado" em sua pretensão de objetividade e cientificidade, o que colocou a análise de implicação 26,27 do grupo no campo pesquisado como uma necessidade incontornável.

Essa condição de duplo ou tríplice estatuto apresenta "vantagens" e "desvantagens", para as quais tivemos que exercer vigilância epistemológica constante. Como "vantagens", podemos apontar a agilidade que tivemos para ir configurando o problema, o nos acercarmos do campo, o compreendermos a linguagem dos sujeitos da pesquisa, em particular quando são próximos a nós, como no caso dos gestores e dos profissionais. Tais "vantagens" rapidamente se transformam em "desvantagens" quando podem dificultar ou mesmo nos impedir de nos abrirmos para as novidades que a empiria foi apontando, em particular novos enunciados, novas possibilidades de pensarmos velhos problemas quando nos aproximamos dos usuários.

A evidenciação da existência e centralidade da regulação leiga, ou do agir leigo, na constituição de "sistemas de saúde" nos interstícios do sistema de saúde formal, produzindo seus mapas de cuidado, só foi possível a partir dessa compreensão. Ou seja, de nossa constante análise de implicação, e claro, pelo diálogo com a literatura já existente sobre o tema.

Reconhecida e valorizada a existência de um agir leigo produtor de mundos, quase sempre invisível ou não valorizado por gestores e profissionais de saúde, tínhamos agora a tarefa de caracterizá-lo melhor, dar mais consistência ao conceito, tentando explicitar melhor suas características e as possíveis implicações para a gestão. Santos 28 (p. 88), ao aprofundar a reflexão crítica sobre a racionalidade do pensamento científico contemporâneo, afirma "que o que a tradição científica e filosófica ocidental conhece e considera importante" não consegue explicar a amplitude e a variedade das experiências sociais presentes hoje no mundo. Para ele, há, na atualidade, um paradoxo epistemológico que atribui uma pobreza à experiência social, retirando a riqueza desse saber como algo válido. Tal posição, 
para o autor, nos impede de revelar a diversidade e a multiplicidade das práticas sociais que fogem das nossas explicações. Para ele, essa atitude expressa uma arrogância de "não se querer ver e muito menos valorizar a experiência que nos cerca, apenas porque está fora da razão com que podemos identificar e valorizar" 28 (p. 93). Assim, no nosso estudo, assumimos os usuários como sujeitos cognoscentes e cognoscíveis. Ao denominarmos "leigos", deslocamos a concepção pejorativa da palavra para uma concepção de um "saber laico-leigo". Ou seja, um conhecimento válido e produzido a partir das experiências sociais vivenciadas pelos usuários na busca pelo cuidado à saúde e, portanto, não filiado (ou referenciado) necessariamente a uma área de conhecimento científico ou profissional especializado.

O conceito de leigo foi construído em torno dos elementos que compõem o estatuto social atribuído ao usuário quando colocado em relação com os profissionais de saúde, em todos os contextos terapêuticos em que se situa essa relação. É considerado um conceito relacional, tal como Norbert Elias 29 o caracterizou. Nesse entendimento relacional do conceito de leigo, o seu estatuto social organiza-se à volta de algumas ideias-chave: ser um mero utilizador dos serviços de saúde; constituir um objeto de conhecimento e não um sujeito do conhecimento; não ser detentor de qualquer forma de conhecimento que possa rivalizar com o conhecimento dos profissionais da Medicina; agir segundo uma racionalidade exclusivamente instrumental por oposição à centralidade da racionalidade científica e técnica da Medicina; conformar-se à posição de aceitação e colaboração do raciocínio clínico, prescindindo do seu raciocínio social sobre a doença, de carácter perceptivo, representativo e avaliativo; assimetria da linguagem na comunicação terapêutica: leiga/linguagem comum versus profissional/linguagem codificada 30,31 .

O móbil do agir leigo são o adoecimento, a dor, o sofrimento e o sentimento de fragilidade inerentes à condição humana. As pessoas movem-se por suas necessidades de saúde, entendidas no seu sentido mais ampliado, incluindo aí a conservação da autonomia no modo de andar a vida, a busca de vínculo e cuidado, o bem-estar, o fim da dor, a alegria de viver, a beleza. Esse é o ponto de partida e o ponto de chegada de todas as narrativas, aquilo que as atravessa do começo ao fim.

A primeira fase da pesquisa já havia oferecido muitas indicações sobre a existência de um regime de regulação leiga, em particular, aquelas dos profissionais de saúde, em função de sua aproximação mais direta com os usuários. Quando iniciamos a coleta das histórias de vida, tal protagonismo leigo ficou ainda mais evidente, autorizando-nos a dizer que não há paciente que, de uma forma ou de outra, não exercite seu posicionamento diante da doença: ao elaborar suas explicações do adoecimento, seja utilizando fartamente o modelo biomédico, com maior ou menor precisão, seja produzindo explicações de ordem mais "subjetiva" ("essa minha doença veio do tempo que cuidei da minha mãe doente”), seja ao procurar estabelecer vínculos com profissionais que funcionem como referência ou uma espécie de "salvo-conduto" ou chave para acessar os recursos necessários para o seu cuidado; ao ir produzindo um aprendizado, muitas vezes na base da tentativa e erro, quase sempre compartilhado com outras pessoas vivendo problema parecido com o seu. Nas sociedades atuais, a Medicina impôs-se como a monopolizadora das respostas para tais necessidades humanas. Uma Medicina institucionalizada, tecnificada, especializada, mas, ainda assim, o "horizonte" no qual os sujeitos do estudo, sejam da primeira ou da segunda fase, reconhecem estar os recursos capazes de suprir tais necessidades. Não adquiriu relevância, durante a pesquisa, o relato de utilização de recursos "alternativos" ou de "práticas populares” para a produção do cuidado, com exceção do relato de uma bem sucedida "terapia religiosa” por uma entrevistada, provavelmente pela importância da Medicina, nas duas cidades estudadas, na composição do cuidado de seus cidadãos.

Podemos identificar três elementos que pautam o agir leigo: (a) reduzir a disjunção entre seu tempo (o tempo vivido da doença/sofrimento), o tempo do gestor (o tempo da racionalização dos recursos dentro de sua governabilidade) e o tempo dos profissionais (o tempo do seu fazer profissional); (b) encontrar o "bom médico"; (c) produzir um "mapa de cuidado" estável, sobre o qual tenha algum controle e previsibilidade.

O "sistema de saúde" do usuário tem sua expressão em um mapa do cuidado. Um mapa do cuidado é formado pelo conjunto de "pontos" de acesso e cuidado que cada pessoa vai produzindo, a partir de suas necessidades e experiências, nos diferentes momentos da vida. Embora haja pontos em comum entre os conceitos de itinerários terapêuticos e mapas de cuidado, esses últimos são formulados na perspectiva de serem utilizados como dispositivo com potencial de incorporação à gestão dos cuidados das pessoas, como instrumento de "negociação terapêutica" e desenvolvimento de estratégias solidárias entre equipe e usuários. Os mapas do cuidado, quando incorporados ao processo de cuidado, são móveis e contingentes e podem ser redesenhados ou reconfigurados continuamente. Os itinerários 
terapêuticos são retrospectivos como podemos ver em alguns estudos desenvolvidos 32,33,34, com especial destaque para a recente e bem cuidada revisão realizada sobre o tema 35 ; os mapas têm uma pretensão prospectiva, ligada ao cuidado, embora tenham, é claro, um componente retrospectivo, de registro e memória, como os itinerários terapêuticos.

Os pontos de acesso do mapa do cuidado podem ser serviços e/ou profissionais com os quais se consegue estabelecer algum tipo de vínculo, passando a ser uma referência dentro do sistema de saúde. O mapa do cuidado ideal é composto preferencialmente por vínculos com profissionais em determinados serviços. Quase sempre o "ponto" é apenas o serviço, como no caso dos serviços de urgência/emergência, sem produção de vínculo profissional.

O mapa é o instrumento ou o dispositivo de operação da regulação leiga. Os pontos de referência do mapa (os serviços e/ou os profissionais) são - quando olhados pelo gestor ou pesquisador - esparsos, fragmentados, sem conexão entre eles. O mapa do usuário conecta, sob a lógica de suas necessidades e dentro de suas possibilidades, os pontos do mapa. O usuário configura seu mapa utilizando-se dos pontos de referência que, olhados "de fora”, aparentemente não configuram nenhum desenho "lógico" se o parâmetro é a já clássica "pirâmide" hierarquizada de serviços. Os pontos do mapa são atravessados por todos os outros regimes de regulação. É nos pontos do mapa que o usuário viverá os outros regimes de regulação.

No atual modo de organização e funcionamento do sistema formal de saúde, não há reconhecimento e valorização dos mapas do cuidado dos usuários como estratégia para a cogestão do cuidado. O mapa do cuidado não é reconhecido nem valorizado. Todo usuário almeja um mapa do cuidado estável, isso é, que tenha "pontos" estáveis, com os quais ele possa contar, nos vários momentos da vida, com suas diferentes necessidades. Há pacientes com mapas mais "completos"; há pacientes que não conseguem produzir mapas (nem conseguem parceria com a equipe para tanto...) e se sentem descuidados, e há pacientes que apenas conseguem esboçar difusamente os contornos de um mapa "possível", pleno de imprevisibilidades.

Para aqueles que utilizam apenas o SUS, o mapa vai sendo produzido a partir da experiência, quase sempre no correr de doença grave ou de problema de saúde crônico, em diferentes graus de coprodução com os serviços/profissionais, mas, às vezes, é um ato muito solitário. O mapa para essas pessoas é produzido na experimentação, por tentativa e erro. Para os possuidores de um "bom" plano de saúde, o mapa, em princípio, está dado ou, pelo menos, seus pontos principais estão bem situados. São "possíveis" conhecidos de antemão. O cliente do plano compra a possibilidade de ter "pontos" garantidos no momento de sua necessidade. Essa é a diferença "vendida”. O cliente compra o plano com a promessa (nem sempre cumprida) de que os pontos do mapa estão previamente garantidos; o cidadão batalha a produção do seu mapa. Um avanço do SUS seria a possibilidade de as equipes de saúde ofertarem ou coproduzirem "mapas de cuidado" dos e com os usuários, o que implicaria em se avançar na compreensão e "aceitação" do caráter misto público-privado inevitável dos mapas de cuidado de pacientes que têm um plano de saúde.

O maior ou menor sucesso, ou a maior ou menor intensidade da regulação leiga, dependerá, sempre, em maior ou menor grau, do encontro com os demais regimes de regulação. Não há, nas atuais condições de institucionalização das práticas de saúde, um agir leigo "autônomo", que não tenha que compor, recompor, atravessar, conectar-se com os outros regimes de regulação. A composição da regulação leiga com a regulação profissional é, quase sempre, o elemento mais determinante para o sucesso do cuidado, particularmente nas situações em que a regulação governamental não consegue viabilizar as respostas necessárias.

Conseguimos identificar três modos principais de operação da regulação profissional: (a) modo burocrático; (b) modo criativo e (c) modo independente, como expresso na Tabela 3. No primeiro, os profissionais subordinam-se inteiramente às normas, aos fluxos, às regras da regulação governamental, o que pode resultar, ou não, no cuidado, a depender, entre outras coisas, da oferta de serviços. No segundo, o profissional conhece e usa as regras e os fluxos "formais" da regulação governamental, utilizando-se de contatos em pontos de sistema e/ou no próprio órgão regulatório para agilizar tempos, conseguir priorizações, estabelecer compromissos etc., a depender de seu interesse e/ou avaliação da necessidade de determinado(s) paciente(s). No modo independente, o profissional produz caminhos totalmente por fora da regulação governamental, por meio de contatos pessoais, uso das relações de influência, de posições privilegiadas, configurando práticas como o "disque amigo", conforme vários relatos de profissionais.

O maior ou menor sucesso do agir leigo dependerá, sempre, das diversas composições que logrará alcançar com esses diferentes modos de regulação profissional.

As narrativas de vida permitiram identificar avanços na regulação governamental nos dois 
municípios estudados, em particular na maior agilidade da realização de exames e acesso a algumas especialidades. No entanto, a média complexidade (as especialidades em particular) segue sendo o "gargalo", pois a alta complexidade acaba sendo melhor solucionada. Às vezes, o avanço da regulação governamental é visto como produtor de barreiras e dificuldades pelos usuários, em particular o "fechamento" de alguns hospitais de maior complexidade. Como expressa Hortênsia: "Eu não estou conseguindo nada (...), antigamente, a gente pegava a carteirinha, a gente esperava e falava: 'Queria uma guia pra tal, tal e tal [na unidade básica de saúde]'. Eles dava guia, a gente ia nos médicos que elas mandava e tudo. Agora não, agora a gente tem que pegar uma folha pra ver se você tem autorização de ir ou de não ir".

O material empírico parece nos autorizar a afirmar que pessoas vivendo situações de graves problemas de saúde, muito utilizadoras de serviços, em particular os especializados e de alta complexidade, de alguma forma já "capturados" ou inseridos em territórios de maior complexidade tecnológica, ainda assim se utilizam dos serviços básicos de saúde, "consumindo" tudo o que eles lhes oferecem para a composição do seu cuidado: medicamentos, transporte, troca de receitas, consultas não agendadas em situações de crise, consultas regulares com o generalista para tratar os problemas mais "simples", em particular hipertensão e diabetes 36 .

\section{Conclusão}

Podemos concluir este trabalho dizendo que os pressupostos iniciais do estudo foram, em boa medida, confirmados: para além da regulação governamental, há outras lógicas regulatórias operando, o que resulta em complexa trama de interações, complementaridades, disparidades e contrastes, mas também disputas de sentidos e modos de se fazer a regulação. Tudo isso nos leva a considerar que a regulação do acesso e consumo dos serviços de saúde, muito mais do que uma atividade burocrático-administrativa, da esfera ou competência governamental, é uma produção social, resultante da ação de uma multidão de atores sociais. Daí sua complexidade e o ponto de partida que deve ser assumido por quem deseja fazer a gestão na saúde de uma perspectiva inclusiva e criativa.
No correr do estudo, foi adquirindo centralidade o que denominamos de agir leigo. Seria o caso, nessa finalização, de relativizar a carga quase depreciativa relacionada ao conceito. Ora, e como vimos antes, por suas origens etimológicas, os leigos seriam pessoas que não possuem conhecimento aprofundado sobre determinada área. No caso da Medicina institucionalizada, os leigos seriam os usuários ou os pacientes, exatamente aqueles que não teriam domínio de seu campo ultraespecializado de conhecimento. Por tudo que vimos nas narrativas, temos que relativizar e superar tal julgamento. Aqueles que poderiam ser denominados de leigos, os "tigres" no linguajar corriqueiro (e depreciativo) da "tribo" dos profissionais de saúde, são menos leigos do que imaginávamos. Pelo contrário, são capazes, a partir de suas experiências com a doença e o sofrimento, de produzir um saber assessor ao saber dos especialistas, com força suficiente para orientar profundas transformações nos modos de se pensar e organizar o cuidado.

Nossos entrevistados revelaram, por suas tocantes narrativas, como são capazes de produzir novos significados para o mundo do cuidado, reivindicar novidades, sugerir saídas para os verdadeiros impasses vividos por aqueles que têm se empenhado em encontrar alguma melhoria para o sistema de saúde. Basta lembrar a generosa apreciação que fazem da rede básica, reconhecendo seu valor de uso e conferindo-lhe novos significados, para além daqueles que têm sido formulados pelas políticas oficiais. Basta lembrar como fazem uso criativo, mais livre, de múltiplas combinações entre o plano de saúde (para aqueles que o têm) e os serviços do SUS, sem as travas que parecem separar rigidamente $o$ que é "público" e o que é "privado", ainda segundo a concepção dos especialistas. Com seu saber assessor, com seu agir "leigo" (intencionalmente entre aspas), homens e mulheres nos deram pistas, no correr da pesquisa, de que há outros arranjos, outros desenhos possíveis de "sistemas de saúde”. O saber assessor produzido pelo agir leigo é, em última instância, o convite irrecusável para experimentarmos, com radicalidade, a cogestão do cuidado entre equipes e usuários, como o caminho mais promissor para a inadiável necessidade de reinvenção da saúde, para a invenção de outros mundos. 


\section{Resumen}

El estudio tuvo como objetivo caracterizar otras lógicas de regulación en la producción de salud, además de la gubernamental. Se trata de una investigación cualitativa en dos etapas, realizada en dos distritos del $A B C D$ Paulista, São Paulo, Brasil. En la primera se llevaron a cabo entrevistas con actores estratégicos (políticos) y con los actores-trabajadores-clave. En la segunda se recogieron historias de vida de 18 personas con un alto nivel de uso de servicios. El análisis de la implicación en el estudio campo permitió a los investigadores una mejor comprensión de los relatos. Se encontraran cuatro sistemas regulatorios (gubernamental, profesional, clientelista y laico), lo que indica que la regulación es un terreno en disputa permanente, una producción social. Los usuarios producen mapas de cuidado que apuntan a otras posibles soluciones para los sistemas de salud, una invitación a experimentar la cogestión entre los equipos y usuarios, como una forma prometedora de la urgente necesidad de reinvención de la salud.

Regulación y Fiscalización en Salud; Prestación de Atención en Salud; Investigación Cualitativa

\section{Colaboradores}

L. C. O Cecilio é o responsável pela concepção da investigação e do artigo, trabalhou na análise e interpretação do material empírico e na redação final. G. Carapinheiro trabalhou na concepção da pesquisa, na metodologia, na análise do material empírico, na revisão crítica do artigo e aprovou a versão final. R. Andreazza trabalhou na coleta e na análise do material empírico e na redação final. A. L. M. Souza, M. G. G. Andrade, S. M. Santiago, C. S. Meneses, D. O. Reis, E. C. Araújo, N. R. S. Pinto e S. M. Spedo trabalharam na coleta e na análise do material empírico, aprovaram a versão do artigo e realizaram a revisão crítica.

\section{Agradecimentos}

Aos mestrandos L. A. Oliveira e S. M. Melo, que ajudaram na coleta das histórias de vida e na análise do material empírico, e T. O. Braz e F. A. O. Albieri, que trabalharam na análise do material empírico e na revisão bibliográfica do artigo. À doutoranda C. R. Magnabosco-Martins e às pesquisadoras L. Teixeira e F. C. B. Campos, que contribuíram na análise dos dados. Aos agentes comunitários em saúde, que indicaram os usuários, e às pessoas que se dispuseram a nos contar suas histórias de vida.

\section{Referências}

1. Boyer R. A teoria da regulação: uma análise crítica. São Paulo: Nobel; 1990.

2. Santos FP, Merhy EE. A regulação pública da saúde no Estado Brasileiro: uma revisão. Inteface Comun Saúde Educ 2006; 10:25-41.

3. Baduy RS, Feuerwerker LCM, Zucoli M, Borian JT. A regulação assistencial e a produção do cuidado: um arranjo potente para qualificar a atenção. Cad Saúde Pública 2011; 27:295-304.

4. Brasil. Portaria MS/GM no 373, de 27 de fevereiro de 2002. Norma Operacional da Assistência à Saúde NOAS-SUS 01/02. Diário Oficial da União 2002; $28 \mathrm{fev}$.

5. Giddens A. A constituição da sociedade. São Paulo: Editora Martins Fontes; 2003.

6. Giddens A, Turner J, organizadores. Teoria social hoje. São Paulo: Editora Unesp; 1999.

7. Domingues JM. Teorias sociológicas no século XX. Rio de Janeiro: Editora Civilização Brasileira; 2001.

8. Thiry-Cherques HR. Pierre Bourdieu: a teoria na prática. Rev Adm Pública 2006; 40:27-55.

9. Gawryszewski ARB, Oliveira DC, Gomes AMT. Acesso ao SUS: representações e práticas de profissionais desenvolvidas nas Centrais de Regulação. Physis (Rio J.) 2011; 19:604-9.
10. Baldwin R, Cave M. Understanding regulation: theory, strategy and practice. New York: Oxford University Press; 1999.

11. Chevalier J. De quelques usages du concept de régulation. In: Miaille $\mathrm{M}$, editor. La régulation entre droit et politique. Paris: L'Harmattan; 1995. p. 71-100.

12. Bertaux D. Narrativas de vida, a pesquisa e seus métodos. São Paulo: Paulus/Natal: EdUFRN; 2010.

13. Arfuch L. O espaço biográfico: dilemas da subjetividade contemporânea. Rio de Janeiro: Editora da UERJ; 2010.

14. Houle G. A sociologia como ciência da vida: a abordagem biográfica. In: Poupart J, Deslauries JP, Groulx AL, Mayer R, Pires A, organizadores. A pesquisa qualitativa: enfoques epistemológicos e metodológicos. Petrópolis: Editora Vozes; 2008. p. 317-34.

15. Schraiber LB. O médico e o seu trabalho: limites da liberdade. São Paulo: Editora Hucitec; 1993.

16. Schraiber LB. O médico e suas interações: a crise dos vínculos de confiança. São Paulo: Editora Hucitec; 2008. 
17. Carapinheiro G. Inventar percursos, reinventar realidades: doentes, trajetórias sociais e realidades formais. Etnográfica 2001; 2:335-58.

18. Gomes MR. Trabalho médico e alienação [Tese de Doutorado]. São Paulo: Faculdade de Medicina, Universidade de São Paulo; 2010.

19. Andreazza R, Carapinheiro G, Teixeira L, Cecilio LCO. Do Centro de Saúde à Unidade de Saúde Familiar: narrativas de ausência e intermitências. Saúde Soc 2011; 20 Suppl 1:S200-1.

20. Other MB, Ayres JRCM. Necessidades de saúde da pessoa com deficiência: a perspectiva dos sujeitos por meio de histórias de vida. Interface Comun Saúde Educ 2012; 16:219-33.

21. Cecilio LCO. Escolhas para inovarmos na produção do cuidado, das práticas e do conhecimento: como não fazermos "mais do mesmo". Saúde Soc 2012; 21:280-9.

22. Saint Pierre HL. Max Weber: entre a paixão e a razão. 3a Ed. Campinas: Editora Unesp; 2004.

23. Certeau MA. A invenção do cotidiano. 17ạ Ed. Petrópolis: Editora Vozes; 2011.

24. Roth JA. Information and the control of treatment in tuberculosis hospitals. In: Friedson E, editor The hospital in modern society. London: CollierMacmillan; 1963.

25. Swaan A. The management of normality: critica essays in health and welfare. London: Routledge; 1990.

26. Altoé S, Lourau R. Analista institucional em tempo integral. São Paulo: Editora Hucitec; 2004.

27. Coimbra C, Nascimento ML. Análise de implicação: desafiando nossas práticas de saber/poder. http:// www.infancia-juventude.uerj.br/pdf/livia/analise. pdf (acessado em 15/Fev/2013).

28. Santos SB. A gramática do tempo: para uma nova cultura política. Porto: Edições Afrontamento; 2006.

29. Elias N. Características universais da sociedade humana. In: Elias N, organizador. Introdução à sociologia. Lisboa: Edições 70; 1999. p. 113-45.
30. Bourdieu P, Winkin Y, Aaron V. Cicourel: le raisonnement medical. Paris: Seuil Coll. Liber; 2002.

31. Alves MFP. A doença mental nem sempre é doença: racionalidades leigas sobre saúde e doença mental. Porto: Edições Afrontamento; 2011.

32. Gerhardt TE. Itinerários terapêuticos em situações de pobreza: diversidade e pluralidade. Cad Saúde Pública 2006; 22:2449-63.

33. Gerhardt TE, Pinheiro R, Mattos RD. Itinerários terapêuticos e suas múltiplas dimensões: desafios para a prática da integralidade e do cuidado como valor. In: Pinheiro R, Mattos RD, organizadores. Razões públicas para a integralidade em saúde: o cuidado como valor. Rio de Janeiro: Instituto de Medicina Social, Universidade do Estado do Rio de Janeiro/ABRASCO; 2007. p. 279-300.

34. Conill EM, Pires D, Sisson MC, Oliveira MC, Boing AF, Fertonani HP. O mix público-privado na utilização de serviços de saúde: um estudo dos itinerários terapêuticos de beneficiários do segmento de saúde suplementar brasileiro. Ciênc Saúde Coletiva $2008 ; 13: 1501-10$.

35. Cabral ALV, Martinez-Hemáez A, Andrade EIG Cherchiglia ML. Itinerários terapêuticos: o estado da arte da produção científica no Brasil. Ciênc Saúde Coletiva 2011; 16:4433-42.

36. Cecilio LCO, Andreazza R, Carapinheiro G, Araújo EC, Adion L, Andrade MGG, et al. Atenção básica à saúde e a construção das redes temáticas de saúde: qual pode ser o seu papel? Ciênc Saúde Coletiva $2012 ; 17: 2893-902$

Recebido em 25/Jun/2013

Versão final reapresentada em 25/Nov/2013 Aprovado em 08/Jan/2014 